\title{
Apresentação
}

DOI: 10.14393/DL31-v1ln4a2017-1

\section{Os estudos enunciativos no Brasil: limites, perspectivas e contribuições}

Na atualidade brasileira, é notório o crescente interesse pelos estudos enunciativos, em suas variadas vertentes teóricas. Sendo o fundamento da enunciação o gesto de apropriação da língua para torná-la apta a um uso específico - influenciar alguém, representar a realidade social etc. - provocado por uma situação de discurso, trata-se de uma conjuntura esperada e compreensível, já que o expurgo do sujeito do espaço político-simbólico da Linguística Moderna pode possibilitar resultados científicos que, no entanto, não apresentam grandes contribuições para a compreensão e para o conhecimento do funcionamento da língua.

O expurgo do sujeito representa, incontornavelmente, um desvio do fundamento da língua. A língua é o meio simbólico humano cuja função basilar é significar. A língua é suporte da significação, e a significação implica, necessariamente, relação discursiva entre sujeitos. Essa é a condição humana da língua, por um lado, e, por outro, a condição do próprio homem no mundo, como já posto por Benveniste (2005, p. 285), “é um homem falando que encontramos no mundo, um homem falando com outro homem”. Colocar a significação no centro do processo de compreensão do funcionamento da língua implica recolocar o objeto da linguística em sua relação fundamental.

O funcionamento da língua coloca em jogo o sujeito no mundo, intentando estabelecer uma relação discursiva com outro(s) sujeito de linguagem e, à ausência de sujeito, não há língua. É nele e por ele que acontece a produção e a manifestação da linguagem. Daí os estudos enunciativos preconizarem que a enunciação pressupõe sujeito que, em ato individual, converta a língua em discurso. Em decorrência, nada está na língua sem ter estado antes em discurso. Nessa perspectiva, a repetição ganha valor linguístico, uma vez que a língua é uma instituição social (com)partilhada por sujeitos, socialmente situados e significados.

Assim sendo, se questionarmos: Onde se encontra a língua?, compreenderemos a relevância dos estudos enunciativos. Não há língua em funcionamento sem sujeito. Também 
não há sujeito sem língua em funcionamento. O sujeito é-feito de seu funcionamento. Fora das relações discursivas, a língua é pura virtualidade; nas relações discursivas, ela é (re)atualizada em forma e sentido. Essa compreensão coloca em relevo autores que se dedicaram, cada um a seu modo, ao estudo da língua em funcionamento. Assim, ganham o espaço político-simbólico brasileiro autores como Bally, Bakhtin, Benveniste, Culioli, Authier-Revuz e Pêcheux, cuja tópica discursiva é recolocar a relação entre língua e sujeito na base de compreensão do funcionamento da língua no e pelo discurso.

No Brasil, os discursos sobre a língua produzidos por esses autores subsidiam a reflexão e a produção de conhecimento sobre o funcionamento da língua nas diversas instâncias de nossa sociedade. Vários pesquisadores brasileiros têm recorrido aos estudos enunciativos para (re)dimensionar a compreensão da comunicação humana e dos mecanismos linguísticos implicados no funcionamento da língua e das diferentes formas da linguagem, uma vez que essa orientação dos estudos sobre a estrutura da língua e de seu funcionamento considera a determinação sócio-histórica e ideológica da língua em uso e dos sentidos por ela passíveis de serem (re)produzidos. Por isso, esse domínio dos estudos linguísticos mostra-se bem consolidado e fecundo em produção de conhecimento no espaço político-simbólico brasileiro.

Além de pesquisas focadas na estrutura e no funcionamento da língua em função do aspecto relacional e discursivo, uma vertente produtiva do domínio dos estudos enunciativos no Brasil encontra-se nas questões relativas ao ensino. Considerado o fundamento enunciativo, essas questões podem ser recolocadas em outros termos, cujo princípio é o exercício da linguagem em diferentes instâncias da sociedade. Essa recolocação muda, sobremaneira, o modo como o ensino e as práticas pedagógicas são (re)vistas e (re)significadas no espaço político-simbólico escolar. Em decorrência, este número da Domínios da Lingu@gem toma a relação entre os estudos enunciativos e o ensino como foco de reflexão, a fim de:

1. descrever e compreender o jogo interlocutivo da aula em função da conjuntura sóciohistórica e ideológica, de forma a evidenciá-la na enunciação em espaço escolar;

2. discutir e analisar a implicação da subjetividade nos processos de ensino e de aprendizagem;

3. descrever como o dizer testemunha a identidade do locutor nos processos enunciativos; 
4. descrever, do ponto de vista enunciativo, mecanismos sintáticos e/ou gramaticais da língua em uso e analisar suas implicações para o ensino de Língua Portuguesa e/ou de línguas estrangeiras.

5. compreender e descrever a relação discursiva (im)posta em sala de aula: que mecanismos de negociação dos sentidos são mobilizados pelos interlocutores? Quais os efeitos por eles produzidos? De que modo esses mecanismos são afetados pela conjuntura sóciohistórica e ideológica?

6. identificar efeitos da política educacional no espaço político-simbólico da sala de aula: qual o impacto no "savoir-faire" dos participantes (professor e aluno)? Implicações na relação com o saber?

7. discutir e analisar tecnologias de ensino, como livro didático e aplicativos, em espaços de ensino e de aprendizagem de Língua Portuguesa e/ou de línguas estrangeiras. Problematizar sua participação na aula: como integrá-las à aula? Como avaliar seus possíveis benefícios ao ensino e à aprendizagem?

Para atingir esses objetivos, os artigos submetidos à publicação neste número foram avaliados por comitê científico especializado. Cada artigo foi analisado por dois avaliadores independentes. Ao término desse processo, foram aprovados pelo comitê científico quatorze artigos para compor o presente número da Domínios da Lingu@gem. Esses artigos contemplam pesquisas desenvolvidas em diferentes regiões do Brasil, o que demonstra que os estudos enunciativos fazem parte dos discursos sobre a língua de e em circulação nacional. Essa representação constitui um índice de sua relevância para os estudos linguísticos e reafirma seu lugar no quadro das pesquisas em linguística no Brasil. Além disso, os artigos são oriundos de diferentes níveis de formação acadêmica, evidenciando sua circulação e seu impacto desde as graduações em Letras até os programas de doutoramento.

Os estudos enunciativos no Brasil descortinam, assim, um campo de questões relevantes e muito instigantes cujo foco é colocar em questionamento a língua em funcionamento no espaço político-simbólico da Educação. Feitas essas ponderações, elencamos os artigos de modo a melhor dar visibilidade à importância e à distribuição dos estudos enunciativos no espaço nacional.

O artigo O homem na língua, de autoria de Maria Inês Pagliarini Cox, Professora da Universidade Federal do Mato Grosso, abre este número da Domínios da Lingu@gem, porque 
Maria Inês é uma precursora nos estudos enunciativos e, assim, intentamos fazer-lhe uma singela homenagem. Desde sua tese de doutorado Je est un mot d'ordre: escritos em torno de sujeito e linguagem e educação, a autora (re)visita a obra de Benveniste e nela encontra caminhos para suas reflexões e trabalhos. Um encontro feliz...

No artigo O homem na língua, a autora faz um tributo a Émile Benveniste, cuja obra tornou-se um pilar dos estudos enunciativos. Nesse tributo, (re)visita um conjunto de estudos realizados por Émile Benveniste entre os anos de 1940 e 1970 em torno das categorias de pessoa, tempo e espaço, a fim de retomar as noções de sujeito e subjetividade e o processo de constituição da linguística da enunciação que excedeu os limites da chamada linguística imanente, ao reintroduzir elementos situacionais na produção do sentido. O artigo também aborda a diferença entre as teorizações de Émile Benveniste e de Michel Pêcheux, este fundador da Análise de Discurso.

O artigo $\mathbf{O}$ funcionamento do vocativo: uma abordagem da enunciação, de autoria de Luiz Francisco Dias, Professor titular da Universidade Federal de Minas Gerais, e Neuza Zattar, Professora da Universidade do Estado de Mato Grosso, além de balizar conceitos da teoria enunciativa proposta pelo semanticista brasileiro Eduardo Guimarães, Professor titular da Universidade Estadual de Campinas, traça uma análise própria do vocativo. Para tanto, os autores estudam o vocativo do ponto de vista da teoria da enunciação, abordando os conceitos de sujeito e interlocução na perspectiva social e histórica.

No artigo $\mathbf{O}$ funcionamento do vocativo: uma abordagem da enunciação, os autores apresentam os conceitos de referencial histórico e pertinência enunciativa fundamentais para a especificação da função do vocativo em termos enunciativos e, com base nesses conceitos, analisam os usos de vocativos em discursos proferidos pela ex-presidente Dilma Rousseff, entre 2011 e 2016. Assim, demonstram que o vocativo participa da relação entre os referenciais históricos da constituição do sentido na interlocução e dos modos de adesão (pertinência) desses referenciais nos enunciados, tratando-se, por conseguinte, da atualização da memória de constituição do outro no enunciado.

O artigo $\mathbf{O}$ ensino de leitura e a formação do sujeito do conhecimento, de autoria de Renata Chrystina Bianchi de Barros, Professora do Programa de Pós-Graduação em Ciências da Linguagem da Universidade do Vale do Sapucaí, problematiza o uso de instrumentos e certas práticas educacionais no ensino de leitura. A autora, a partir de uma posição discursiva, mostra 
que capacitar, preparar e adequar o sujeito para práticas cotidianas promove o controle e a ordenação do trabalho de interpretação.

No artigo $\mathbf{O}$ ensino de leitura e a formação do sujeito do conhecimento, Renata Chrystina mostra uma possibilidade de promover o deslocamento do sujeito de uma posição que identifica sentidos na superfície do texto para uma posição em que a articulação do objeto simbólico a processos significativos da vivência no mundo do leitor provoque a produção de conhecimento. Para tanto, a autora analisa uma cartilha distribuída pela Secretaria Municipal de Educação do Rio de Janeiro aos alunos matriculados no $4^{\circ}$ ano do Ensino Fundamental, material com o qual os alunos acompanham as aulas regulares de língua portuguesa e leitura.

O artigo "Nós vamos ter que dar dez beijos em cada um": a gênese de discurso direto em um processo de escritura a dois, de autoria de Eduardo Calil, Professor da Universidade Federal de Alagoas, e Kall Anne Amorim, Professora da Faculdade Estácio de Alagoas, discute o processo genético e criativo do discurso direto produzido por uma dupla de alunas recém-alfabetizadas (6-7 anos), diante da solicitação do professor de que combinassem e escrevessem um texto em sala de aula.

No artigo "Nós vamos ter que dar dez beijos em cada um": a gênese de discurso direto em um processo de escritura a dois, os autores, com base nos pressupostos teóricos e metodológicos da Genética Textual e da Linguística da enunciação, analisam o registro fílmico do processo de escritura. Os autores identificaram que a gênese textual da fala de um personagem passa por intensas (re)formulações antes de sua inscrição e linearização na folha de papel. Eduardo e Kall Anne também observaram que a criação e o registro escrito do discurso direto são influenciados pelo conteúdo narrado, bem como pela condição letrada e pela subjetividade dos escreventes novatos.

O artigo Poesia em sala de aula: (re)leituras e sentidos possíveis, de autoria de Karine Rios de Oliveira Leite, Professora de Língua Portuguesa no Instituto Federal de Goiás (IFG), Campus Águas Lindas, e Thiago André Rodrigues Leite, Professor de Língua Portuguesa e Língua Inglesa no Instituto Federal de Goiás (IFG), Campus Águas Lindas, discorre sobre a poesia no plano semântico, pensando certas "escolhas lexicais", em detrimento de outras possíveis, presentes em certos poemas brasileiros, e possibilidades de (re)leituras dessas “escolhas” em momentos de sala de aula. 
No artigo Poesia em sala de aula: (re)leituras e sentidos possíveis, os autores, mobilizando teorizações de Émile Benveniste, compreendem ser imperiosa a experiência, em sala de aula, de abordar semanticamente a poesia, com a abertura a (re)leituras de diferentes “escolhas lexicais” presentes em poemas. Assim procedendo, os autores trazem contribuições importantes para o ensino de leitura de poesia no espaço escolar. Trata-se, portanto, de um trabalho que encontrou nas questões de ensino seu lugar de reflexão.

O artigo Letramento e Enunciação: bases para um diálogo, de autoria de Giovane Fernandes Oliveira, Graduado em Licenciatura em Letras, com ênfase em Língua Portuguesa, Língua Francesa e suas Literaturas, pela Universidade Federal do Rio Grande do Sul, lança bases para um diálogo entre os estudos do letramento acadêmico e os estudos enunciativos, em especial àqueles filiados ao pensamento de Émile Benveniste.

No artigo Letramento e Enunciação: bases para um diálogo, o autor propõe um modelo enunciativo de letramento acadêmico, no qual o locutor-aluno instaura-se como sujeito de linguagem no mundo letrado acadêmico por meio das relações enunciativas com o alocutário-professor/colegas e com as culturas de escrita acadêmica, renovando sua relação com a língua a cada vez que insere seu discurso no mundo letrado acadêmico para falar, ouvir, ler e produzir textos escritos e orais letrados. Esse trabalho também encontrou nas questões do ensino seu lugar de reflexão e contribuição.

O artigo Um convite a problematizar o ensino de escrita sob a perspectiva enunciativa benvenistiana, de autoria de Jorama de Quadros Stein, Professora de Leitura e Produção de textos na Universidade Tecnológica Federal do Paraná, problematiza o ensino de escrita. Do ponto de vista analítico, centra-se na categoria a referência sobre escrita, a fim de identificar a constituição a noção de escrita mobilizada no relato. Os recortes analisados mostram que a escrita é abordada como gramática, como processo, como elaboração, como desafio e como experiência. Além disso, a escrita é compreendida como uma forma da linguagem que supõe interlocução.

No artigo Um convite a problematizar o ensino de escrita sob a perspectiva enunciativa benvenistiana, Jorama explicita que a suposição de interlocução, aliada à noção de escrita em Benveniste, inaugura uma necessidade de mobilização da escrita que convoca uma experiência de enlace na e pela linguagem. Essa experiência está em função de que se efetive uma escrita que, antes de servir para comunicar, sirva para viver. 
O artigo A passagem do aluno do Ensino Médio ao Superior e seus efeitos no discurso: uma análise enunciativa, de autoria de Carolina Knack, Professora da Universidade Federal do Rio Grande, mostra como se constitui a passagem de aluno de Ensino Médio para aluno de Ensino Superior, tendo em vista a posição de locutor no discurso.

No artigo A passagem do aluno do Ensino Médio ao Superior e seus efeitos no discurso: uma análise enunciativa, a autora, inspirada em teorizações de Benveniste, mobiliza, no trabalho de análise, duas interlocuções orais com uma aluna participante de um projeto. A partir desse arcabouço teórico, fundamenta a passagem de posições da locutoraaluna, mostrando o caráter duplo da linguagem, que é ser individual e social. Esse caráter duplo abre horizontes para se pensar em relações outras com o outro e com a língua, a depender da pessoa linguística, do tempo e do espaço.

O artigo Os valores culturais integrando forma e sentido nas relações enunciativas criança-outro no ato de aquisição da linguagem, de autoria de Isadora Laguna Soares, Mestranda do Programa de Pós-graduação em Letras, da Universidade Federal do Rio Grande do Sul, aborda o modo como a criança é inscrita nos valores culturais que as formas da língua, atualizadas em discurso, comportam.

No artigo Os valores culturais integrando forma e sentido nas relações enunciativas criança-outro no ato de aquisição da linguagem, a autora mostra que os morfemas da língua, que são formas que integram níveis inferiores ao da frase, evidenciam valores culturais em sua constituição de forma-sentido. Assim, propõe um diálogo conceitual entre os estudos enunciativos de Benveniste e os estudos de aquisição de língua materna, concentrando-se em fatos de linguagem recortados de Silva (2009). Isadora, na esteira de Silva (2009), defende a perspectiva de que a aquisição é um ato enunciativo.

O artigo Em busca da coincidência: traços de responsabilidade enunciativa, de Ilderlândio Assis de Andrade Nascimento, Doutorando no Programa de Pós-Graduação em Linguística, da Universidade Federal da Paraíba, investiga a responsabilidade enunciativa em monografias de conclusão de curso, focando como categoria de análise os fenômenos da modalização autonímica/as não-coincidências do dizer, a partir dos postulados da Análise Textual dos Discursos (ATD). Para tanto, o autor analisa dez monografias de conclusão do curso de Letras. 
No artigo Em busca da coincidência: traços de responsabilidade enunciativa, Ilderlândio mostra que a não-coincidência entre as palavras e as coisas e a não-coincidência das palavras consigo mesmas constituem traços de responsabilidade enunciativa, tendo em vista que o sujeito, ao enunciar, busca restabelecer a coincidência rompida pelo não-um dos sentidos. Em um caso, a coincidência entre a palavra - o simbólico - e o objeto de discurso - a realidade a ser nomeada, e, em outro, entre a coincidência entre uma palavra e outra.

O artigo Dizer sobre outro e falar de si: um estudo da constituição do sujeito a partir de diários reflexivos, de autoria de Maria Ester Vieira de Sousa e Julia Cristina de Lima Costa, ambas Professoras da Universidade Federal da Paraíba, aborda alguns diários reflexivos produzidos por alunos de um Curso de Letras a distância, a fim de aferir o modo como os seus autores significam sua reflexão e sua prática docente.

No artigo Dizer sobre outro e falar de si: um estudo da constituição do sujeito a partir de diários reflexivos, as autoras analisam, com base na teoria de Bakhtin em diálogo conceitual com as teorizações de Bauman (2005) e de Hall (2008), a escrita dos diários reflexivos, para mostrar como essa escrita é constituída por uma dialogia e alteridade, que acaba por marcar o processo de formação dos alunos escritores dos diários.

O artigo Polifonia como estratégia no processo de recontextualização da ciência no gênero reportagem televisiva, de autoria de Patrícia Santos Albarello, graduada em Letras/Português, pela Universidade de Franca, e Najara Ferrari Pinheiro, Professora da Universidade de Franca, analisa e problematiza as vozes que constituem e atravessam reportagens de popularização da ciência.

No artigo Polifonia como estratégia no processo de recontextualização da ciência no gênero reportagem televisiva, as autoras centram-se na análise do programa "Globo Ecologia”, transmitido pela Rede Globo de Televisão. Produzindo um diálogo teórico entre Análise Crítica do Discurso, Teoria da Representação dos Atores Sociais e pressupostos da teoria bakhtiniana, as autoras mostram como se constitui a recontextualização do conhecimento especializado da ciência para a divulgação ao público telespectador do programa analisado, a fim de explicitar como a polifonia pode ser vista como estratégia de recontextualização.

O artigo Inserção das tecnologias digitais na educação: tessitura identitária docente na modernidade tardia, de autoria de Janicleide Vidal Maia e Avanúzia Ferreira Matias, ambas Professoras de Língua Portuguesa e suas respectivas literaturas da Educação Básica 
Estadual do Ceará, aborda relatos produzidos por uma professora do ensino básico, de modo a mostrar como se constitui a identidade docente diante da inserção de tecnologias digitais no espaço de sala de aula.

No artigo Inserção das tecnologias digitais na educação: tessitura identitária docente na modernidade tardia, as autoras, inscritas no âmbito da Teoria SistêmicoFuncional, focalizam o posicionamento da professora em relação à identificação e à atitude reflexiva diante de sua própria prática pedagógica, para mostrar os efeitos da modernidade tardia na constituição da identidade docente.

O artigo Para além das Vidas Secas, Resistência: Linguagem-Poder, de autoria de Teodulino Mangueira Roseando, Doutorando do Programa de Pós-graduação em Ciências da Linguagem, da Universidade do Sul de Santa Catarina, parte do princípio de que a linguagem se configura como lugar de interação humana, implicando o quê o autor denomina de linguagem-poder.

No artigo Para além das Vidas Secas, Resistência: Linguagem-Poder, Teodulino mostra como alunos sertanejos do ensino médio produzem uma (re)leitura da obra "Vidas Secas”. Essa (re)leitura acaba por deflagrar elementos históricos e culturais do nordestino, pois a linguagem subjetiva o homem. Por meio da Análise de Discurso francesa de base peucheutiana, o autor analisa poemas e fotos, produzindo decorrências teórico-analíticas para o princípio linguagem-poder, dadas as condições de produção das materialidades que ele mobiliza nas análises.

Como já ressaltamos, esse conjunto de artigos revela o interesse e o alcance dos estudos enunciativos. Há muitos pesquisadores voltados à perspectiva da língua em uso e ação, bem como à implicação dessa perspectiva para a reflexão sobre a Educação. Movidos pelo desejo de enfocar e de interrogar a língua em uso e ação, os autores em tela lançam-se à tarefa de questionar as evidências e ao empreendimento de analisar e de problematizar a implicação da enunciação a diferentes corpora. Trata-se de conceituações e de práticas de análise diferentes, com um intuito em comum: colocar o sujeito e a subjetividade na agenda científica brasileira em termos de pesquisas realizadas ou em andamento.

É chegada a hora de irmos aos artigos propriamente ditos. Antes, contudo, gostaríamos de agradecer aos autores cujos trabalhos integram este número da Domínios da Lingu@gem. Se é importante se lançar à produção de conhecimento, é verdade também a relevância de se 
fazer circular as produções. Deixamos ao leitor o deleite da leitura e o prazer do trabalho com a língua em uso e ação. Boa leitura a todos!

Cármen Agustini (UFU)

João de Deus Leite (UFT)

\section{Referências}

BAUMAN, Z. Identidade. Rio de Janeiro: Zahar, 2005.

BENVEnISTE, É. [1958]. Da subjetividade na linguagem. In: BENVENISTE, É. Problemas de Linguística Geral I. Campinas, SP: Pontes, 2005.

HALL, S. A identidade Cultural na Pós-Modernidade. Rio de Janeiro: DP\&A, 2006.

SILVA, C. L. da C. A criança na linguagem: enunciação e aquisição. São Paulo: Pontes, 2009. 